\title{
Molecular Targets in Lung Cancer Therapy: A Current Review
}

\section{Luís Pinho"\#, Fernando Mendes ${ }^{2-4 \#, ~ M a r i a ~ M a n u e l a ~ R o d r i g u e s ~}{ }^{5}$, Jéssica Estrela ${ }^{2}$, Ricardo Jorge Teixo ${ }^{3}$ and Rui Santos Cruz ${ }^{1 \star}$}

${ }^{1}$ Polytechnic Institute of Coimbra, ESTESC-Coimbra Health School, Department of Pharmacy, Coimbra Portugal

${ }^{2}$ Polytechnic Institute of Coimbra, ESTESC-Coimbra Health School, Department of Biomedical Laboratory Sciences, Coimbra, Portugal

${ }^{3}$ Biophysics Unit-IBILI, Faculty of Medicine of University of Coimbra, Portugal

${ }^{4}$ Center of Investigation in Environment, Genetics and Oncobiology (CIMAGO), Faculty of Medicine of University of Coimbra, Portugal

${ }^{5}$ Farmacy, Coimbra University Hospital, Coimbra, Portugal

"Both authors had the same contribution for this paper

\begin{abstract}
Lung cancer presents a heterogeneous nature, which became more and more evident. Generally this type of cancer in an advanced state has a poor prognosis. The discovery of multiple molecular mechanisms, associated to the development, proliferation and prognosis of lung cancer has created new opportunities for a targeted therapy, improving clinical results. Non-small cells lung cancer is characterized by mutations on Epidermal Growth Factor Receptor and/or in the signaling pathways related to this receptor, which promoted the development of selective monoclonal antibodies and Epidermal Growth Factor Receptor-Tirosine Kinase Inhibitors, blocking the proliferation, differentiation, angiogenesis and tumor survival.
\end{abstract}

Thus, our review highlighted the importance of a continuous research of new molecular targets in lung cancer to achieve better therapeutic outcomes and overall survival rates.

Keywords: Directed therapy; Personalized therapy; Molecular targets and Lung cancer

\section{Introduction}

Cancer incidence worldwide has been increasing over the years [1]. Lung cancer (LC) is a disease with a poor prognosis once diagnosed. LC is the leading cause of death in men worldwide and the second cause of mortality in women [2-4]. In Portugal, LC remains as the leading cause of death due cancer in men [5].

LC origins from oncogenic alterations in tissues from the respiratory epithelium, namely in bronchi, bronchioles and alveoli [6]. This cancer results from multiple morphological, molecular and genetic changes, leading to an accumulation of malignant cells [7-9]. LC is mainly classified into two categories, according to its histological characteristics: non-small cell lung cancer (NSCLC) and small cell lung cancer (SCLC). NSCLC is categorized into three different categories, namely adenocarcinoma, squamous cell carcinoma and large cell carcinoma. NSCLC is the most common LC type (about $80 \%$ of total cases) and adenocarcinoma is the most common subtype (about 40\%). Moreover, bronchioloalveolar carcinoma subtype is more associated with women and non-smokers. In contrast, squamous cell carcinoma is linked to tobacco consumption [2,10-12]. On the other hand, SCLC tends to affect the neuroendocrine system and is related to smoking habit, being diagnosed in only $1 \%$ of non-smokers patients [2].

Classification and staging of LC are critical for definitive diagnosis, treatment strategy and to predict the patient's outcome [2]. Treatment choice depends on a number of factors that are relate to the patient and the tumour, including histology, tumour stage and biology and the general health of the patient $[13,14]$. LC treatment is based on a set of procedures such as surgery, chemotherapy and radiotherapy [15]. Chemotherapy is widely used in cancer treatment, however, is rarely effective in this type of cancer due to the low amount of drug available in the lung tissue, even if administered in high doses [16].

Recently, it has been investigated a large number of molecular changes such as mutations and gene amplification [17] that could be responsible for tumour survival and directly affect prognosis. Treatments based upon these changes are called targeted or personalized therapies. These treatment protocols aim to target common molecular changes and may increase the survival rate in nonsurgical stages $[18,19]$. Specific therapy can be used to identify patients at risk for disease, regarding their genomic profile, and provide the appropriate drug with administration of a specific dose at the right time [20]. Thus, there are some mediators which may play a predominant role in the treatment of LC, such as Epidermal Growth Factor Receptor (EGFR), Vascular Endothelial Growth Factor (VEGF), [21], Anaplastic Lymphoma Kinase (ALK), among others [18].

Thus, this study aims to highlight the importance of targeting therapies in lung cancer treatment.

\section{Materials and Methods}

This study consists in a review of the literature concerning targeted therapies focused at molecular targets in lung cancer.

The survey of information was carried out in online databases, namely PubMed and Medline database. In this research it was used the keywords: "personalized treatment" and "lung cancer".

An initial trial of papers of interest was performed by the relevance of the title and content of abstract. Pre-selected articles were completely analysed and properly selected. Selection was performed based on the inclusion criteria: papers in English or Portuguese; review articles or original research papers available in free full text. Exclusion criteria were established as unavailability of selected papers in free full text and papers published before 2005 .

*Corresponding author: Rui Santos Cruz, Rua 5 de Outubro, São Martinho do Bispo, 3046-854 Coimbra, Portugal, Tel: +351917060167; E-mail: ruic@estescoimbra.pt

Received September 21, 2015; Accepted October 05, 2015; Published October 15,2015

Citation: Pinho L, Mendes F, Rodrigues MM, Estrela J, Teixo RJ, et al. (2015) Molecular Targets in Lung Cancer Therapy: A Current Review. J Integr Oncol 4: 148. doi:10.4172/2329-6771.1000148

Copyright: ( 2015 Pinho L, et al. This is an open-access article distributed under the terms of the Creative Commons Attribution License, which permits unrestricted use, distribution, and reproduction in any medium, provided the original author and source are credited. 
In addition to this, it was also used some information contained in technical books. Finally, all ethical questions have been fulfilled, and all the sources that provided the theoretical support have been properly referenced.

\section{Results}

Our survey highlighted the importance of the exploration of specific genetic alterations described in lung cancer cells. Several studies had already described the role of molecular targets such as EGFR and ALK in the development and progression of lung cancer, namely in the cases of NSCLC. However there are other oncogenic alterations in genes that have been identified in NSCLC that we reported in this review as follows, namely VEGF, BRAS, KAS and MET [22]

\section{Epidermal growth factor receptor (Egfr)}

EGFR is a transmembrane glycoprotein that plays an important role in carcinogenesis [18]. This receptor is also a critical component of signalling pathway activation, including Ras-Raf-MEK and PI3KAkt-mTOR pathways [23-25]. EGFR is a member of the tyrosine kinase family and therefore have a response of about $70 \%$ to tyrosine kinase inhibitors (TKI) [22].

In NSCLC, EGFR dysregulation has been shown and it could be due to different mechanisms, including overexpression and gene amplification. This receptor has a higher expression in the case of nonsmokers and women [26].

EGFR-TKI are a class of drugs well tolerated. However, this class of drugs can induce low to moderate cytotoxic effects at dermatological and gastrointestinal systems [27,28]. Currently, most widely used EGFR-TKI are Gefitinib [29] and Erlotinib. Both are able to inhibiting the catalytic activity of the receptor and thereby inhibiting its auto phosphorylation. This way signal transduction pathway could be inhibited and thus it can induce an anti-tumour effect [18,30]. In a study conducted in Asia and Europe, both drugs showed a very similar activity spectrum, with differences in pharmacokinetics and bioavailability, where Erlotinib showed a higher bioavailability [27].

Another strategy to inhibit the activity of EGFR is the use of monoclonal antibodies, such as cetuximab, panitumumab and others that block ligand binding to the receptor [31]. This type of treatment does not inhibit auto phosphorylation of the tyrosine kinase domain through constitutive activation. Therefore, these mutations can still activate other pathways that regulate cell cycle progression, cell growth and angiogenesis [32,33].

\section{Vascular endothelial growth factor receptor (Vegfr)}

VEGF is a major mediator of angiogenesis and it has been found to be overexpressed in several tumours in advanced stages. Higher levels of VEGF has been described in squamous cell carcinoma adenocarcinoma [34]. VEGF family is composed of different proteins denominated VEGF-A, VEGF-B, VEGF-C, VEGF-D and placental growth factor (PIGF) [18]. VEGF-A is the most important member, since it is primarily responsible for physiological and pathological mechanisms of angiogenesis. It normally acts by binding to VEGFR-2, causing a signalling cascade. This cascade leads to the activation of transcription factors in the nucleus and, consequently, the formation of new vessels [35].

In tumour cells, this pathway is involved in the induction of tumour cells self-survival and proliferation, as well as formation of new vessels in solid tumours which is essential for the nutrition of tumour cells and its survival [26].
VEGF function can increase mitosis rate of endothelial cells, control vascular permeability and consequently the survival of the vascular endothelium, mechanisms that are activated by the binding of VEGF to its receptors (VEGFR-1, VEGFR-2 and VEGFR-3) $[18,26]$.

VEGF, by its crucial role in carcinogenesis and tumour progression, is an important molecular target for the development of cancer targeted therapies. Bevacizumab is a monoclonal antibody that binds to VEGF-A and is able to neutralize VEGFR isoforms. It was observed that treatment with Bevacizumab increases the risk of bleeding, especially into tumours located near the great vessels related to squamous cell carcinoma.

The dual inhibition of EGFR and VEGF is also a treatment option currently used and it could be performed under two strategies. The first one is the combination of two specific anti-targeted drugs such as Erlotinib and Bevacizumab, and the second one is the use of an agent with dual activity, Vandetanib, which is a small molecule with antiVEGFR-2, - 3 and anti-EGFR activity [18].

\section{Anaplastic lymphoma kinase (Alk)}

ALK is a member of tyrosine kinase receptors [36,37], namely insulin superfamily, which is normally expressed in the central nervous system, small intestine and testis $[31,38]$.

EML4-ALK is a fusion protein which results from a short reversal in chromosome 2 and that comprises the intron 13 of EML4 and the intron 19 of ALK, generating an oncogenic fusion encoding a constitutively activated protein [32]. This protein has been found to be overexpressed in some patients with NSCLC. EML4-ALK is able to inhibit apoptosis, thereby favouring proliferation of tumour cells [39]. It is more common in younger patients, non-smokers or smokers with low concentration of accumulated tobacco and adenocarcinoma $[18,40]$. This translocation is usually linked to unique mutations in EGFR or KRAS and is also associated with resistance to treatment based in EGFR-TKI [31].

Crizotinib was approved for the treatment of patients with mutations in ALK and it was found that it induced a better outcome than common chemotherapy. However, a minority of patients with NSCLC, who had EML4-ALK mutation did not respond to treatment based on Crizotinib which was attributed to mutations related with ALK [41]. Ceritinib (inhibitor of ALK) was approved in April 2014 by the Food and Drug Administration (FDA) for the treatment of patients with NSCLC with resistance to Crizotinib [42].

Braf: BRAF gene encodes a protein (serine/threonine kinase) which has a very important role at KRAS signalling pathway. BRAF is related to activation of important cellular functions, including proliferation and cell survival $[31,32]$. B-RAF, is a RAF kinase which is one of three members of this family: A-RAF, B-RAF and RAF-1 (also known as c-RAF) [31]. Both KRAS and BRAF are intervenient of signalling cascade of EGFR family proteins.

Mutations in BRAF can be found in about 1-3\% in LC cases, mainly in adenocarcinoma. These are unique mutations in EGFR and KRAS and tend to be associated to a poor response to treatment with EGFRTKI [32].

Some specific inhibitors of BRAF have been approved by the FDA, such as Vemurafenib and Dabrafenib. This drugs act at specific mutations in BRAF-V600E, however only 40 to $50 \%$ of patients with BRAF mutation have this specific mutation in BRAF-V600E. 
For patients with a mutation in BRAF (V600E-free), are still being developed targeted-therapies $[43,44]$.

Kras: Ras proteins or P21 Ras belong to the superfamily guanosinetriphosphate where the three best-known members are KRAS, HRAS and NRAS [10].

KRAS is a GTPase usually located on cell membrane and it is activated by receptors of transmembrane growth factor such as EGFR, HER2, ALK, FGFR and MET [45]. Point mutations in some aminoacids could lead to a compromised GTPase activity. This could result in constitutive activation of downstream signalling cascades. These mutations are found in about 20 to $30 \%$ of lung cancer adenocarcinomas [46] and are usually present in conjunction with other mutations in other genes [47].

Usually KRAS is inactivated after GTP to GDP conversion, leading to regulation of cell proliferation and growth. Mutations in KRAS gene result in conversion of GTP to GDP, which induces uncontrolled growth and proliferation of tumour cells [42].

There is currently no effective targeted therapy approved for mutations in the KRAS gene due to loss of normal enzymatic function of Ras [48], which could represent an important area of research in the near future.

\section{Mesenchymal epithelial transition factor (Met)}

MET is a proto-oncogene located on chromosome 7q21, which encodes a transmembrane receptor tyrosine kinase, the hepatocyte growth factor receptor (HGFR) [31,49]. It can induce inhibition of EGFR protein and then may be a "kinase switch" to ensure cell survival [50].

An increase of MET expression means an acquired resistance to EGFR-TKI and about $20 \%$ of patients with resistance to EGFR-TKI treatment had shown an increased amplification of the MET [42,50,51].

There are already some MET inhibitors, such as Cabozatinib that have been approved by FDA for the treatment of specific cancers, but still no clinical evidence on the efficacy of Cabozatinib in patients with NSCLC [42].

\section{Conclusion}

In the last years, it has been made a significant improvement in the knowledge and perception of biological complexity of the tumour and its microenvironment. This improvement allowed starting a new era of targeted therapy for lung cancer treatment. These new therapeutic strategies based on the identification of specific molecular targets in cancer development and progression mechanisms aims to customize and drive these targets drugs with greater efficacy.

Genetic changes that occur on tumour cells allow oncogenic deregulation of tumour suppressor genes as well as overexpression or activation of genes that promote cancer growth. Structural changes in tyrosine kinase receptors lead to proliferation of tumour cells and thereby creating opportunities for personalized therapy.

Thus, therapy with, for example, EGFR-TKIs and ALK inhibitors, has provided a new treatment for patients diagnosed with lung adenocarcinoma. However, resistance to targeted therapy remains a major obstacle to satisfactory clinical results.

Nowadays, there is a great effort to identify new targets and drugs that can improve the actual therapeutic outcome in which concerns lung cancer treatment. However, this research is still in development, where the great majority of the studies have not yet pass through clinical trials. Most of the targets that are being studied are not fully described and understood, which can lead to the development of several selective drugs for the same molecular target.

Thus, we believe that, in the future, a continuous effort to overcome resistance to targeted therapies already applied in the clinical practice would be of great importance in the advance of LC treatment. Moreover, it is also of crucial importance the continuous study of molecular pathways described as essential for tumour development and progression and the development of new targeted drugs designed to block these pathways.

This research, hopefully, will allow not only a better outcome but also the elimination of severe side effects such those observed in the common chemotherapeutic regimens and a significant increase in quality of life and long-term survival.

\section{References}

1. Teixeira SF, Guimarães Idos S, Madeira KP, Daltoé RD, Silva IV, et al. (2013) Metformin synergistically enhances antiproliferative effects of cisplatin and etoposide in $\mathrm{NCl}-\mathrm{H} 460$ human lung cancer cells. J Bras Pneumol 39: 644-649.

2. Mendes F, Antunes C, Abrantes AM, Gonçalves AC, Nobre-Gois I, et al. (2015) Lung cancer: the immune system and radiation. Br J Biomed Sci 72: 78-84.

3. Travis WD (2011) Pathology of lung cancer. Clin Chest Med 32: 669-692.

4. Shimizu K, Okita R, Nakata M (2013) Clinical significance of the tumor microenvironment in non-small cell lung cancer. Ann Transl Med 1: 8-10.

5. Hespanhol V, Parente B, Araújo A, J. Cunha, A. Fernandes, et al. (2014) Cancro do pulmão no norte de Portugal?: um estudo de base hospitalar. Port J Pulmonol 19: 245-251.

6. Longo DL, Fauci A, Kasper D, Hauser S, Jameson JL, et al. (2011) Harrison's Principles of Internal Medicine, (18th edtn). McGraw-Hill.

7. Davidson MR, Gazdar AF, Clarke BE (2013) The pivotal role of pathology in the management of lung cancer. J Thorac Dis 5 Suppl 5: S463-478.

8. Cagle PT, Allen TC, Dacic S, Beasley MB, Borczuk AC, et al. (2011) Revolution in lung cancer: new challenges for the surgical pathologist. Arch Pathol Lab Med 135: 110-116.

9. Andrews TD, Baird JW, Wallace WA, Harrison DJ (2011) Routinely obtained diagnostic material as a source of RNA for personalized medicine in lung cancer patients. J Thorac Oncol 6: 884-888

10. Raparia K, Villa C, DeCamp MM, Patel JD, Mehta MP (2013) Molecular profiling in non-small cell lung cancer: a step toward personalized medicine. Arch Pathol Lab Med 137: 481-491.

11. MacConaill LE1 (2012) Advancing personalized cancer medicine in lung cancer. Arch Pathol Lab Med 136: 1210-1216.

12. Yoshiyama K, Terazaki Y, Matsueda S, Shichijo S, Noguchi M, et al. (2012) Personalized peptide vaccination in patients with refractory non-small cell lung cancer. Int J Oncol 40: 1492-1500.

13. Mollberg N, Surati M, Demchuk C, Fathi R, Salama AK, et al. (2011) Mindmapping for lung cancer: towards a personalized therapeutics approach. Adv Ther 28: 173-194.

14. Fortunato O, Boeri M, Verri C, Moro M, Sozzi G1 (2014) Therapeutic use of microRNAs in lung cancer. Biomed Res Int 2014: 756975.

15. Hammerschmidt S, Wirtz H (2009) Lung Cancer: Current Diagnosis and Treatment. Dtsch Arztebl Int 106: 809-821.

16. Long J, Cheang T, Zhuo S, Zeng RF, Dai QS, et al. (2014) Anticancer drugloaded multifunctional nanoparticles to enhance the chemotherapeutic efficacy in lung cancer metastasis. J Nanobiotechnology 12: 1-11.

17. Tovar I, Expósito J, Jaén J, Alonso E, Martínez M, et al. (2014) Pattern of use of radiotherapy for lung cancer: a descriptive study. BMC Cancer 14: 697.

18. Parente Lamelas I, Abal Arca J, Fírvida Pérez JL (2012) Directed therapies in lung cancer: new hope? Arch Bronconeumol 48: 367-371. 
Citation: Pinho L, Mendes F, Rodrigues MM, Estrela J, Teixo RJ, et al. (2015) Molecular Targets in Lung Cancer Therapy: A Current Review. J Integr Oncol 4: 148. doi:10.4172/2329-6771.1000148

19. Chung TW, Tan K, Chan H, Lai MD, Yen MC et al. (2014) Induction of Indoleamine 2 , 3-dioxygenase ( IDO ) Enzymatic Activity Contributes to Interferon-Gamma Induced Apoptosis and Death Recetor 5 Expression in Human Non-small Cell Lung Cancer Cells. Asian Pacific J Cancer Prev 15 $7995-8001$.

20. SÅ,odkowska J, Rojo MG (2011) Digital pathology in personalized cancer therapy. Folia Histochem Cytobiol 49: 570-578.

21. Gold KA, Wistuba II, Kim ES (2012) New strategies in squamous cell carcinoma of the lung: identification of tumor drivers to personalize therapy. Clin Cancer Res 18: 3002-3007.

22. Roh MS (2014) Molecular Pathology of Lung Cancer: Current Status and Future Directions. Korean Acad Tuberc Respir Dis 3536: 49-54.

23. Villaruz LC, Socinski MA (2011) Personalized therapy for non-small cell lung cancer: which drug for which patient? Semin Thorac Cardiovasc Surg 23: 281 290

24. Qu Z, Song A, Feng W, Teng R, Gao J, et al. (2014) Grandinin down-regulates phosphorylation of epidermal growth factor receptor. Int J Clin Exp Pathol 7 : 5888-5894.

25. Liu R, Liu X, Zheng Y, Gu J, Xiong S, et al. (2014) MicroRNA-7 sensitizes nonsmall cell lung cancer cells to paclitaxel. Oncol Lett 8: 2193-2200.

26. West L, Vidwans SJ, Campbell NP, Shrager J, Simon GR, et al. (2012) A novel classification of lung cancer into molecular subtypes. PLoS One 7: e31906.

27. Antonicelli A, Cafarotti S, Indini A, Galli A, Russo A, et al. (2013) EGFR-targeted therapy for non-small cell lung cancer: focus on EGFR oncogenic mutation. Int J Med Sci 10: 320-330.

28. Asami K, Atagi S (2014) Epidermal growth factor receptor tyrosine kinase inhibitors for non-small cell lung cancer. World J Clin Oncol 5: 646-659.

29. Chen L, Chen R, Zhu Z, Zhang Y, Wen Z, et al. (2014) Predictive factors associated with gefitinib response in patients with advanced non-small-cell lung cancer (NSCLC). Chin J Cancer Res 26: 466-470.

30. Varella-Garcia M (2010) Chromosomal and genomic changes in lung cancer. Cell Adh Migr 4: 100-106.

31. Planchard D (2013) Identification of driver mutations in lung cancer: first step in personalized cancer. Target Oncol 8: 3-14.

32. Cheng L, Alexander RE, Maclennan GT, Cummings OW, Montironi R, et al (2012) Molecular pathology of lung cancer: key to personalized medicine. Mod Pathol 25: 347-369.

33. Chen J, Zheng X, Liu DY, Zhao Q, Wu YW, et al. (2014) Therapeutic effects and adverse drug reactions are affected by icotinib exposure and CYP2C19 and EGFR genotypes in Chinese non-small cell lung cancer patients. Asian Pac J Cancer Prev 15: 7195-7200.

34. Heuvers ME, Aerts JG, Cornelissen R, Groen H, Hoogsteden HC, et al. (2012) Patient-tailored modulation of the immune system may revolutionize future lung cancer treatment. BMC Cancer 12: 580.
35. de Mello RA, Costa BM, Reis RM, Hespanhol V (2012) Insights into angiogenesis in non-small cell lung cancer: molecular mechanisms, polymorphic genes, and targeted therapies. Recent Pat Anticancer Drug Discov 7: 118-131.

36. Hartel PH, Hartel J V, Fanburg-smith JC, Julie C, Gilmore RW, et al. (2013) Toward Personalized Medicine of Lung Cancer?: Response to Nontargeted Therapy in Invasive Pulmonary Adenocarcinoma as a Function of Tumor Cell Differentiation. Int J Surg Pathol 21: 224-228.

37. Symposium L (2013) Personalized medicine: Lung Cancer leads the way. Indian J Cancer 50: 2013-2015.

38. Shaw AT, Ou S-HI, Bang YJ, Ross Camidge, Benjamin J. Solomon, et al (2014) Crizotinib in ROS1 -Rearranged Non-Small-Cell Lung Cancer. N Engl J Med 371:1963-1971.

39. Nishino Mizuki, Jagannathan JP, Krajewski KM, O'Regan, K, Hatabu, H, et al. (2012) Personalized Tumor Response Assessment in the Era of Molecular Medicine: Cancer-Specific and Therapy-Specific Response Criteria to Complement Pitfalls of RECIST. AJR Am J Roentgenol 198: 737-745.

40. Kobayashi K, Hagiwara K (2013) Epidermal growth factor receptor (EGFR) mutation and personalized therapy in advanced nonsmall cell lung cancer (NSCLC). Target Oncol 8: 27-33.

41. Moreira AL, Thornton RH (2012) Personalized Medicine for Non - SmallCell Lung Cancer: Implications of Recent Advances in Tissue Acquisition for Molecular and Histologic Testing. CLLC 13: 334-339.

42. Haghgoo SM, Allameh A, Mortaz E, Garssen J, Folkerts G, et al. (2015) Pharmacogenomics and targeted therapy of cancer: Focusing on non-smal cell lung cancer. Eur J Pharmacol 754: 82-91.

43. Okimoto RA, Bivona TG (2014) Recent advances in personalized lung cancer medicine. Per Med 11: 309-321.

44. Forde PM, Ettinger DS (2013) Targeted therapy for non-small-cell lung cancer: past, present and future. Expert Rev Anticancer Ther 13: 745-758.

45. Dienstmann R, Martinez P, Felip E (2011) Personalizing therapy with targeted agents in non-small cell lung cancer. Oncotarget 2: 165-177.

46. Cagle PT, Allen TC, Olsen RJ (2013) Lung cancer biomarkers: present status and future developments. Arch Pathol Lab Med 137: 1191-1198.

47. Girard N (2013) Other signalization targets. Target Oncol 8: 69-77.

48. Kerr KM (2012) Personalized medicine for lung cancer: new challenges for pathology. Histopathology 60: 531-546.

49. Kim HS, Mitsudomi T, Soo RA, Cho BC (2013) Personalized therapy on the horizon for squamous cell carcinoma of the lung. Lung Cancer 80: 249-255.

50. Dacic S (2011) Molecular diagnostics of lung carcinomas. Arch Pathol Lab Med 135: 622-629.

51. Früh M (2011) The search for improved systemic therapy of non-small cell lung cancer--what are today's options? Lung Cancer 72: 265-270. 